Keywords: Self-injurious behaviour, Epidemiology, rate, Incidence, Parasuicide, Suicide.

\title{
The Epidemiology of parasuicide in Canary Islands
}

\author{
F. Rodríguez Pulido \\ M.E. Méndez Abad \\ F. González de Chaves González \\ D. Montesdeoca Hernández \\ E. González Dávila
}

Department of Psychiatry. Social and Community Unit. La Laguna University. La Laguna. Tenerife. Canary Islands

SPAIN

\begin{abstract}
Objective: To analyze the epidemiology of parasuicide in Canary Islands.
Methods: Emergency Department reports at every Hospitals and clinical data of all Mental Health Units were revised in Tenerife (1992-1996) and in Gran Canaria (1994-1996). Data about age, sex, address, educational level, marital status, job situation, time and methods used for committing parasuicide and previous parasuicide events were collected.

Results: In Tenerife Island the annual average was 355 parasuicides among which $24.9 \%$ of the episodes were repeaters. The average crude rate was 70.99 cases per 100.000 inhabitants and the standardized rate was 61.81 . In Gran Canaria Island the annual average was 634 and $21.3 \%$ were repeaters. The average crude rate was 120.23 per 100.000 and the standardized rate was 103.7 per 100.000 . The age group 15-34 years, showed the higher rate values. Women presented higher rates as compared to men in all age categories.

Conclusion: These findings are in agreement with those of the WHO-EURO Multicentre Project on Parasuicide. We found in Tenerife the lowest parasuicide rate values published in Europe.
\end{abstract}

\section{Introduction}

Suicidal behaviour has gained recognition as a serious problem of Public Health. In the ICD-9 it was included as illness, since until then, it was interpreted merely as symptoms of it. The term parasuicide was used for the first time by Kreitmann ${ }^{1}$ in 1977 and the
World Health Organization (WHO) defines it as a non fatal deliberate self-harm where the motivation is irrelevant, thus including the acts considered as manipulation.

The majority of parasuicidal persons are below age 35 and constitute a pool from which many of the future suicides are drawn. In developed countries suicide ranks 
among the top 10 causes of death for individuals of all ages and the greatest predictor of eventual suicide is parasuicide ${ }^{2}$.

The WHO/EURO Multicentre Project on Parasuicide ${ }^{3,4}$ drew data from different sites. The data analized by Schmidtke showed that the rate of parasuicide varies substantially across sites and show higher values for females. In Guipúzcoa (Spain) we have observed the lowest rates for men (45 per 100,000 inhabitants) and for women (60 per $100,000)$.

In the Canary Islands the suicide rate during the period $1977-1983$ was 8.1 per $100,000^{5}$, increasing the risk of suicide with age and showing is the highest values for separated and divorced ${ }^{6}$ people, but parasuicide rates are unknown.

The aim of the present study was to obtain data about epidemiology of parasuicide in Tenerife and Gran Canaria (Canary Islands).

\section{Material and methods}

This study comprises the investigation of parasuicides in Tenerife (from January 1, 1992 to December 31, 1996) and in Gran Canaria Island (from January 1, 1994 to December 31, 1996) occurred involving people of age 15 and older.

The population in Tenerife was 485,428 inhabitants of age 15 and older and in Gran Canaria were 521,2347. Tenerife and Gran Canaria have two Public Reference Hospitals each and there are nine Mental Health Units in Tenerife and eight in Gran Canaria where only outpatients are treated.

All the Emergency Hospital Department reports and all the Mental Health Units clin- ical data were revised. Data about age, sex, address, educational level, civil state, job situation, methods used for committed parasuicide and previous parasuicide events were collected.

The European Standard Population data (International Agency for Research in cancer, Lyon, WHO) were used for the direct standardization of the rates, as well as the WHO-EURO project.

\section{Results}

During the studied periods, 1,679 persons committed 1,773 parasuicides in Tenerife with an annual average of 355 whereas 1,622 persons committed 1,902 parasuicide attempts in Gran Canaria, with an annual average of 634 .

Table I shows the social and demograhic data. A variable percentage of data was not detailed in the reviewed files thus being the total different than $100 \%$.

In Tenerife island, 1331 people committed a parasuicide index in the five years period studied (75\% of the episodes) while the other 348 persons $(24.9 \%$ of the episodes) had previously committed parasuicide (i.e. they were repeaters: 106 within the analyzed period and 242 having previous acts). 585 (33\%) were committed by men and 1188 (67\%) by women. The average crude rate was 70.99 cases per 100,000 (49 men and 92 women) and the standardized rate was 61.81 (42 men and 81 women). In Gran Canaria, along the three years period studied, 1276 people committed a parasuicide index $(78.7 \%$ of the episodes) and 346 (21.3\%) were repeaters (143 within the analyzed period and 203 having previous antecedents). 768 (40.4\% 
of the episodes) were committed by men and $1,134(59.6 \%)$ by women. The average crude rate was 120.23 per 100,000 (100 per 100,000 in men and 140 per 100,000 in women) and the standardized rate was 103.7 per 100,000 ( 85 per 100,000 in men and 122 per 100,000 in women).

The crude and standardized rate for agegroups in Tenerife and Gran Canaria are listed in Table II. The higher rates are found in the age groups [15-24] and [25-34]. Women present higher rates in all age category groups as compared to men.

Table III shows the methods used for committing parasuicide. 3,049 (82.9\%) persons performed self poisoning acts and 401 $(10.9 \%)$ a self-injury acts. The most common self poisoning was benzodiazepines overdose $(31 \%)$.

Table I

Social and demographic characteristics in the sample.

\begin{tabular}{|c|c|c|}
\hline & Tenerife $(\%)$ & Gran Canaria (\%) \\
\hline \multicolumn{3}{|l|}{ Marital status } \\
\hline Single & 25.5 & 22.6 \\
\hline Married & 19.6 & 17.9 \\
\hline Separated/divorced & 7.4 & 5.9 \\
\hline Widowed & 1.2 & 1.0 \\
\hline \multicolumn{3}{|c|}{ Change in marital status (6 months) } \\
\hline Yes & 2.5 & 1.6 \\
\hline No & 35.5 & 27.2 \\
\hline \multicolumn{3}{|l|}{ Educational level } \\
\hline Low & 18.7 & 13.2 \\
\hline Intermediate & 9.2 & 7.2 \\
\hline High & 11.9 & 2.7 \\
\hline \multicolumn{3}{|l|}{ Profession } \\
\hline Students & 11 & 6.6 \\
\hline Farmer & 1.8 & 1.3 \\
\hline Industrial & 1.1 & 1.5 \\
\hline Services & 14.8 & 9.8 \\
\hline \multicolumn{3}{|l|}{ Other } \\
\hline Ocupational labor & 14.7 & 9.5 \\
\hline Active/Employed & 12.3 & 10.4 \\
\hline Active/Unemployed & 3.7 & 3.6 \\
\hline Inactive & 24.8 & 15.2 \\
\hline
\end{tabular}

Table II

Crude and standardized parasuicide rates (per 100.000 population and year) in relation to age group and sex

\begin{tabular}{|c|c|c|c|c|c|c|c|c|}
\hline \multirow[t]{3}{*}{ Age group } & \multicolumn{4}{|c|}{ Men } & \multicolumn{4}{|c|}{ Women } \\
\hline & \multicolumn{2}{|c|}{ Tenerife } & \multicolumn{2}{|c|}{ Gran Canaria } & \multicolumn{2}{|c|}{ Tenerife } & \multicolumn{2}{|c|}{ Gran Canaria } \\
\hline & Crude & Standard & Crude & Standard & Crude & Standard & Crude & Standard \\
\hline $15-24$ years & 63 & 9 & 108 & 15 & 175 & 25 & 245 & 35 \\
\hline 25-34 years & 65 & 9 & 176 & 25 & 107 & 15 & 176 & 25 \\
\hline $35-44$ years & 48 & 7 & 88 & 12 & 81 & 11 & 131 & 18 \\
\hline $45-54$ years & 31 & 4 & 65 & 9 & 52 & 7 & 73 & 10 \\
\hline$\geq 55$ years & 17 & 4 & 24 & 5 & 25 & 5 & 34 & 8 \\
\hline
\end{tabular}


Table III

Methods used for commiting parasuicides.

\begin{tabular}{lrrr} 
& Tenerife & Gran Canaria & All TF + GC (\%) \\
\hline Self- poisoning & $\mathbf{1 , 4 8 0}$ & $\mathbf{1 , 5 6 9}$ & $\mathbf{3 , 0 4 9}(\mathbf{8 2 . 9 6 \%})$ \\
Analgesics & 130 & 156 & $7.78 \%$ \\
Anxiolytics-hypnotics & 496 & 648 & $31.12 \%$ \\
Antidepressants-antipsychotic & 60 & 51 & $3.02 \%$ \\
Central Nervous System agents & 49 & 59 & $2.93 \%$ \\
Other drugs & 182 & 91 & $7.42 \%$ \\
Several drugs & 316 & 270 & $15.94 \%$ \\
Alcohol & 21 & 12 & $0.89 \%$ \\
Chemical products, fumes or pesticides & 86 & 73 & $4.32 \%$ \\
Self-injury & $\mathbf{2 2 6}$ & $\mathbf{1 7 5}$ & $\mathbf{4 0 1}(\mathbf{1 0 . 9 1 \%})$ \\
Hanging or strangulation & 9 & 27 & $0.97 \%$ \\
Drowning & 6 & 5 & $0.29 \%$ \\
Shooting, explosive & 6 & 3 & $0.24 \%$ \\
Fire, hot vapour & 4 & 12 & $0.43 \%$ \\
Cutting & 124 & 102 & $6.14 \%$ \\
Jumping from height & 52 & 42 & $2.55 \%$ \\
Jumping in front of traffic & 8 & 5 & $0.35 \%$ \\
Traffic & 4 & 1 & $0.13 \%$ \\
Other & 15 & 8 & $0.62 \%$ \\
Self poissoning + injury & $\mathbf{1 3}$ & $\mathbf{4 2}$ & $\mathbf{5 5}(\mathbf{1 . 4 9 \%})$ \\
No listed & 54 & 116 & $170(4.62 \%)$ \\
TOTAL & $\mathbf{1 , 7 7 3}$ & $\mathbf{1 , 9 0 2}$ & $\mathbf{3 , 6 7 5}$ \\
\hline
\end{tabular}

No significant differences either in the month, day of the week or seasonal distribution of the attempts were observed. Most events $(84.4 \%)$ occur within "social activity hours" (from 4 p.m. to 12 p.m.) and only $15.6 \%$ along the dawn.

The diagnosis according to CIE-10 was picked up in a low percentage $(2.5 \%$ to $10.5 \%)$. A syndromic diagnosis was present only in $39.5 \%$ of the revised files. Mood disorders were present in $14.9 \%$ of persons who had committed a parasuicide index and $27 \%$ in the repeaters.

Rates varied considerably with location. The highest parasuicide rate in Gran Canaria was found in Telde (182 per $100,000)$ and the lowest in Firgas (51 per 100,000). In Tenerife the highest rate was found in San Miguel de Abona (165 per
100,000) and the lowest rate in La Orotava (10 per 100,000).

\section{Discussion}

The registration-based studies may miss a substantial number of people who never seek treatment. However, the data in this study are based on the review of all Hospital Emergency Department reports and all Mental Health Units patient files of the Public Sanitary System along the analyzed periods. Arensman ${ }^{8}$ shows that $28 \%$ of parasuicide people are assisted by family doctors and do not go to any hospital, but the usual practice in our area is that these patients are then followed by a psychiatrist and a psychologist in the Mental Health Unit of reference. Thus, 
we have increased the proportion of parasuicide registered in this study. Parasuicide rate in Tenerife and in Gran Canaria may differ and be higher that what we show. However, we think that sociodemographic features are well reflected because of this is a deep study extended in time ( 5 years in Tenerife and 3 in Gran Canaria data collection) with 3,675 parasuicide cases registered.

As in other studies ${ }^{9,10}$, this one shows significant differences in the parasuicide rate between male and female. In both islands, within all age-groups, the rate was higher in females than in males, except in the 25-34 age category in Gran Canaria, where male and female rate were equal.

Surprisingly, the crude and standardized rate were higher in Gran Canaria (crude: 120 per 100,000; standardized: 103 per 100,000) than in Tenerife (crude: 71 per 100,000; standardized 61.8 per 100,000$)$. Tenerife shows the lowest rate in Europe, and this satnds for males and females. The ratio (male/female) in Tenerife was $1 / 2$ and in Gran Canaria 2/3. The differences in rates between localities and between islands cannot be explained for traditions, customs, religious convictions, social viewpoints or climatic conditions although these variables have not been studied.

Figure 1 shows the standardized rates from the WHO study adding Tenerife and Gran Canaria rate values. Higher rates were found among young people. Figure 2 shows that among men, the highest rates were within age 25-34 years, the same as in ten centres in the WHO study (i.e. Padua, Berna, Helsinki...); among females, the 15-24 age category, showed the highest rate, as in seven centres in the WHO study (i.e. Umea, Burdeos, Pontoise...) $)^{3,4}$. Most studies ${ }^{11}$ also show the highest rates among women in their teens to early twenties, and men in their twenties. The lowest rates both for males and females correspond to age groups 55 and older. More than 80 percent of people who committed parasuicide are 44 years old or less. 65 percent of people in Tenerife and 68 percent in Gran Canaria were in the 15-24 age category.

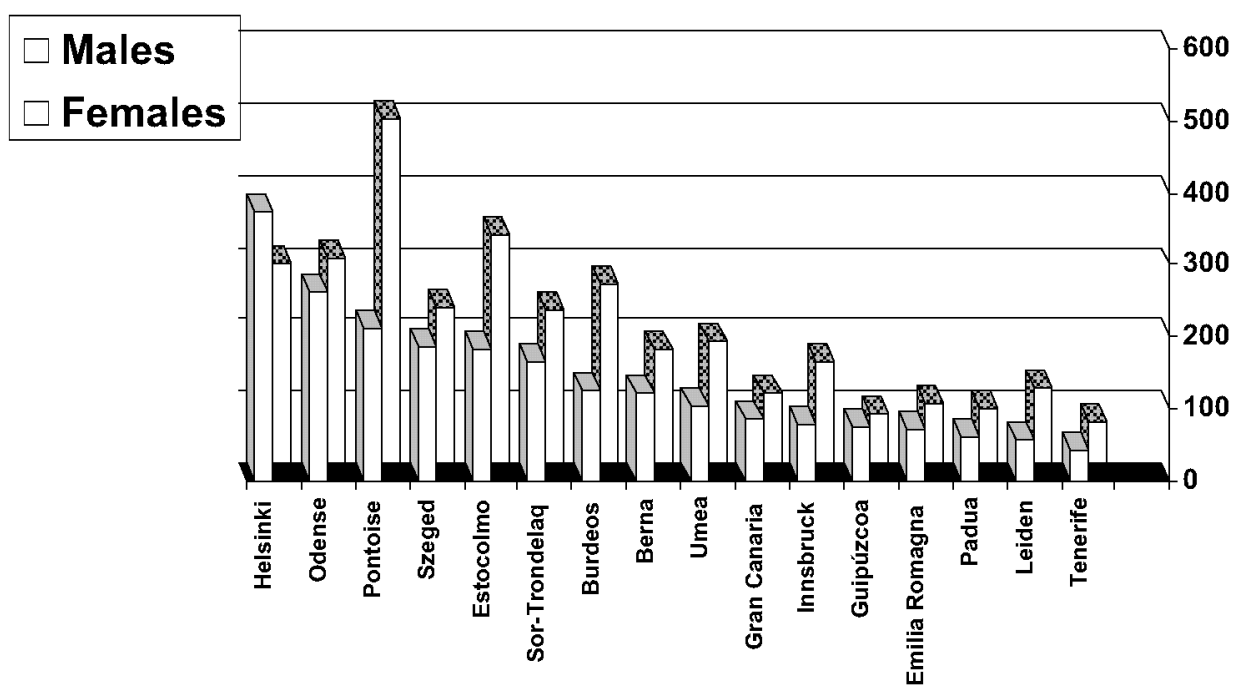

Figure 1. Parasuicide standardized rates in the centres of WHO study and in Canary Islands. 


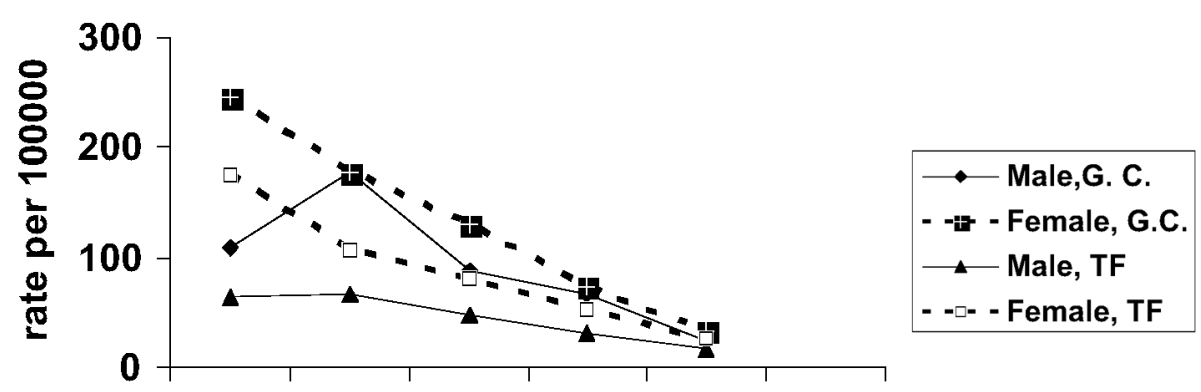

15-24 25-34 $35-44 \quad 45-54>55$

age category

Figure 2. Parasuicide and age groups: male and female crude tases.

Previous parasuicide is highly predictive of future parasuicide ${ }^{2}$. In the present study, 24.9 percent of parasuicidal persons in Tenerife and 21 percent in Gran Canaria had commited previous parasuicide. In Tenerife 106 persons $(6.3 \%)$ repeated at least one parasuicide act in the five-year period analyzed, whereas 143 persons $(8.8 \%)$ repeated at least one parasuicide in Gran Canaria in the three-years period analyzed. In the WHO study this proportion was higher: $42 \%$ of males and $45 \%$ of females had had a previous parasuicide attempt ${ }^{4}$.

Table III shows the method used for committing parasuicide. According it, we can observe the self-poisoning as the most frequent $(83 \%)$ and specially the benzodiazepines overdose. The most violent methods (auto-injury) appear related to males. Other studies show similar results ${ }^{12}$.

The distribution of parasuicides according to marital status show that single people has the highest average rate. Although this result is at most partial due to the high proportion of young people in the sample, similar findings have been reported elsewhere $^{4,13}$. Unemployment has long been thought to increase the risk of parasuicide ${ }^{14}$. We found a high proportion of unemployed people but data show a high proportion of young students too

\section{Conclusions}

The present study shows the epidemiology of parasuicide in Canary Island. Our findings are in agreement with those of the WHO-EURO Multicentre Project on Parasuicide. As in the WHO study, women appear to have higher rates of parasuicide than men; younger age groups of both males and females show the highest rates.

There is a considerable and unexplained variation in rates between islands and localities; and up to $24.9 \%$ parasuicides committed had a previous history of deliberate selfharm. We found in Tenerife the lowest parasuicide rate published in Europe.

\section{Acknowledgement}

The research was supported by a grant from Fundación Canaria de Investi- 


\section{gación y Salud "FUNCIS" (Gobierno de Canarias).}

\section{References}

1. Kreitmann NS. Parasuicide. Chichester: Wiley; 1977.

2. Diekstra RFW. The epidemiology of suicide and parasuicide. Acta Psychiatr Scand 1993; (Suppl 371): 9-20.

3. Platt S, Bille-Brahe U, Kerkhof A, Schmidtke A, Bjerke T, Crepet $\mathrm{P}$ et al. Parasuicide in Europe: the WHO/EURO multicentre study on parasuicide. I. Introduction and preliminary analysis for 1989. Acta Psychiatr Scand 1992; 85: 97-104.

4. Schmidtke A, Bille-Brahe U, Deleo D, Kerkhof A, Bjerke T, Crepet $\mathrm{P}$ et al. Attempted suicide in Europe: rates, trends and sociodemografic characteristics of suicide attempters during the period 1989-1992. Results of the WHO/EURO Multicentre Study on Parasuicide. Acta Psychiatr Scand 1996; 93(5): 327-338.

5. Rodríguez-Pulido F, Sierra A, Gracia R, Doreste J, Delgado S, González-Rivera JL. Suicide in the Canary Islands, 1977-1983. Acta Psychiatr Scand 1991; 84: 520523.

6. Rodríguez-Pulido F, Sierra A, Doreste J, Gracia R, González-Rivera JL. Suicide in the Canary Islands: standardized epidemiological study by age, sex, and marital status. Soc Psychiatry Epidemiol 1992; 27: 69-74.
7. Instituto Nacional de Estadística (INE). Censo de población y viviendas 1991.

8. Arensman E, Kerhof AJFM, Hengelveld MW, Muldeer JD. Medically treated suicide attempts: a four year monitoring study of the epidemiology in The Netherlands. J Epidemiol Community Health 1995; 49: 285-289.

9. Diekstra RFW. Suicide and the attempted suicide: an international perspective. Acta Psychiatr Scand 1989; 80 (Suppl 354): 1-24.

10. Weissman A. The epidemiology of suicide attempts, 1961-1971. Arch Gen Psychiatr 1974; 30: 737-746.

11. Welch SS. A Review of the Literature on the Epidemiology of Parasuicide in the General Population. Psychiatr Serv 2001; 52: 368-375.

12. Gallego JCF, Páramo Fernández M, Gude Sanpedro F. Perfil de los intentos de suicidio en el servicio de urgencias de un hospital. Psiquis 1993; 14(5): 20-26.

13. Hawton K, Fagg J, Simkin S, Mills J. The epidemiology of attempted suicide in the Oxford area, England (1989-1992). Crisis 1994; 15(3): 123-135.

14. Platt S. Unemployment and suicidal behavior: a review of the literature. Soc Sci Med 1984; 19: 93-115.

Address for correspondence: Francisco Rodríguez Pulido Department of Psychiatry La Laguna University Medical School 38270-La Laguna. Tenerife. Spain Telephone number: +34922319278 Fax number: +34 922319279 e-mail: fpulido@ull.es SPAIN 


\section{Linguistics \& Language Behavior Abstracts}

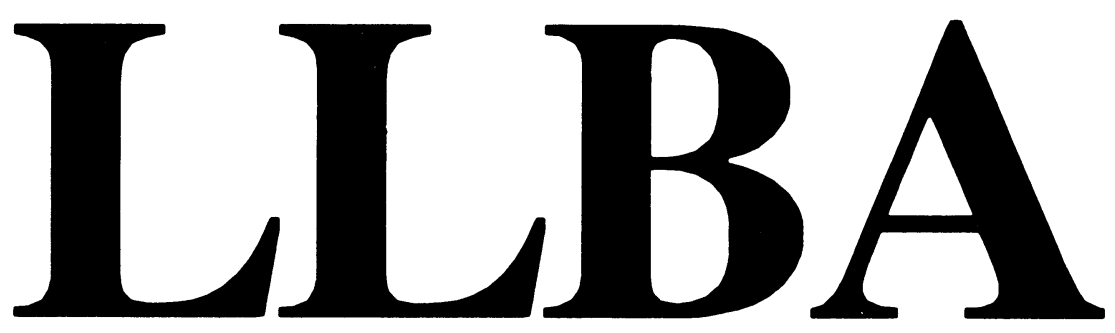

Now entering our 26 th year 135,000 abstracts to date) of senvice to linguists and language researchers worldwide. LLBA is available in print and also online from BRS and Dialog.

Linguistics \& Language Behavior Abstracts

$$
\text { P.O. Box } 22206
$$

San Diego, CA 92192-0206

Phone (619) 695-8803 FAX (619) 695-0416

Fast, economical document delivery available. 